\title{
Development of Novel Membranes Based on Electro-spun Nanofibers and Their Application in Liquid Filtration, Membrane Distillation and Membrane Adsorption
}

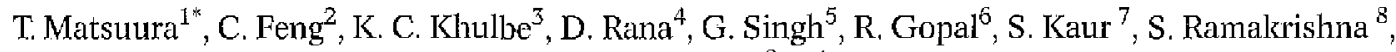 \\ $\&$ S. Tabe ${ }^{9}$ \\ 1,2,3,4 55 Industrial Membrane Research Laboratory, Department of Chemical and Biological Engineering, \\ University of Ottawa, 161 Louis Pasteur, Ottawa, Ont. K1N 6N5, Canada \\ ${ }^{6,7 \& 8}$ NUS Nanoscience \& Nanotechnology Initiative, Department of Mechanical Engineering, \\ National University of Singapore \\ ${ }^{9}$ Ministry of the Environment, Environmental Sciences and Standards Division, 40 st. Clair Ave. West, \\ Toronto, Ont. M4V 1M2, Canada
}

\begin{abstract}
'
Electro-spinning is known as a simple and versatile method to produce nonwoyen membranes made out of nanofibers. A wide range of polymers and blends can be used to yield nanofibers. Commonly used membrane polymers such as cellulose acetate (CA), polysulfone (PSU) and polyvinylidene lluoride (PVDF) have been successfully electro-spun to form nonwoven nanofiber membranes for water filtration. Investigations have revealed that electro-spun nanofibrous membranes (ENMs) possess high-flux rates and low transmembrane pressure. These characteristics are due to its (1) high porosity, (2) interconnected open pore structure and (3) tailorable membrane thickness. Although electro-spun membranes have been extensively studied for decades and successfully commercialized as air filtration membrane, they have not been applied tor water treatment. The nanofiber membranes were used recently at the Industrial Membrane Research Laboratory of the University of Ottawa with the collaboration of Nanoscience \& Nanotechnology Initiative of the National University of Singapore for the following investigations.

a. Removal of latex particles from water: PVDF nanofiber membranes were subjected to filtration of latex particles $(0.1$ to $10 \mu \mathrm{m})$ at the feed pressure of 0.6 bar gauge $[1,2]$.

b. Seawater desalination by membrane distillation: PVDF nanofiber membranes were subjected to desalination of aqueous NaCl solutions by air gap membrane distillation $[3,4]$.

c. Trihalomethanes (THMs) and haloacetic acids (HAAs) removal by carbonized polyacrylnitrile (PAN) nanofiber membranes $[5,6]$.
\end{abstract}

Keywords: Electro-spun nanofiber membrane, microfiltration, air gap membrane distillation, membrane adsorption, carbonized membranes, seawater desalination, THMs HAAs removal

\subsection{INTRODUCTION}

Electro-spinning has gained increasing momentum as a viable process to create sub-micron to nanoscale fibers through an electrically charged jet of

\footnotetext{
* Corresponding to: T. Matsuura (email: matsuara@eng.uottawa. ca)
}

polymer/solution melt. A large amount of research has been carried out to obtain thorough understanding of the process to control the fiber formation. Electro-spun nanofiber membranes cover a wide range of applications including air filters, but they have not been used for water treatment. 
Electro-spun nanofiber membranes (ENMs) possess several attractive attributes that may make them desirable in separation technology, such as high porosity, pore sizes ranging form sub-micron to several nicrometers, interconnected open pore structure, high permeability and a large surface area/volume ratio.

Taking advantage of ability to produce submicron fibers with relative ease and cost effectively, it is believed that a highly efficient fibrous filter for liquid separation can be produced.

This paper is the summary of current activities at the Industrial Membrane Research Laboratory of the University of Ottawa, together with the National University of Singapore, on applications of electro-spun nanofiber membranes for water treatment. The membranes were effectively applied for particulate removal as pre-filters $[1,2]$, for seawater desalination by air-gap membrane distillation $[3,4]$ and the removal of trihalomethanes (THMs) and chloroacetic acid (CAAs) by membrane adsorption after carbonization [5, $6]$. The details of the membrane preparation, characterization and performance testing methods and results are outlined.

\subsection{EXPERIMENTS AND RESULTS}

\subsection{Removal of Latex Particles from Water}

Twenty percent (w/v) polysulfone (PSU, Mn 26,000, Aldrich, USA) was prepared in N,Ndimethylformamide (Fisher Scientific, USA). The polymer was electro-spun at a rate of $4 \mathrm{~mL} / \mathrm{h}$. A high voltage $(12 \mathrm{kV})$ was applied between the needle tip of the spinneret and the collecting metal plate (distance $15 \mathrm{~cm}$ ). The fiber diameter was $470 \mathrm{~nm}$ and the thickness of the nanofiber membrane was $135 \mu \mathrm{m}$. The pore size distribution was determined by a capillary flow porometer (Porous Materials Inc., USA). The largest pore, the bubble point, was $4.6 \mu \mathrm{m}$. From the water flux versus pressure profile, the liquid entry pressure of water was found to be $1.8 \mathrm{psi}$.

The membranes were subjected to the particlechallenge test using polystyrene (PS) microparticles of sizes from 0.1 to $10 \mu \mathrm{m}$. For the particles of 7 to $10 \mu \mathrm{m}$, the particle rejection was more than 99\%. Although there was slight decrease from the initial flux, the flux was recovered almost completely. Since these particles are greater than the maximum pore size $(4.6 \mu \mathrm{m})$ the rejection is due to the size rejection.

For the particle sizes of $0.1,0.5$ and $1 \mu \mathrm{m}$, the flux profile and membrane performance are summarized in Table 1.

Table 1 Performance of polysulfone nanofiner membrane in the particle-challenge test

\begin{tabular}{|c|c|c|c|c|}
\hline $\begin{array}{l}\text { Particle } \\
\text { size, } \mu \mathrm{m}\end{array}$ & $\begin{array}{l}\text { Initial } \\
\text { water } \\
\text { flux } \\
\text { lkg/h m }\end{array}$ & $\begin{array}{l}\text { Final } \\
\text { water } \\
\text { flux } \\
\text { lkg/h m }\end{array}$ & $\begin{array}{l}\text { Flux } \\
\text { recovery, } \\
\%\end{array}$ & $\begin{array}{l}\text { Particle } \\
\text { rejection, } \\
\%\end{array}$ \\
\hline 1. & 2284 & 675 & 30 & 92 \\
\hline 0.5 & 2462 & 1120 & 45 & 47 \\
\hline 0.1 & 2772 & 2684 & 97 & 14 \\
\hline
\end{tabular}

${ }^{a}$ Water flux before the particle separation experiment was made

${ }^{\mathrm{b}}$ Water flux after the particle separation experiment and the subsequent washing was made

It should be noted that in Table 1 there is a sharp decline of flux when the particle size is 1 $\mu \mathrm{m}$. It is due to the formation of solid calke layer at the membrane surface. It is well known that the least migration of the particles away from the surface due to the Brownian diffusion and by the particle lift force causes the severest particle precipitation to the surface that occurs when the particle size is about $1 \mu \mathrm{m}$. Nanoparticles were not observed inside the membrane or at the bottom of the membrane. The high particle separation is enabled in the presence of the cake layer. In the separation of $0.5 \mu \mathrm{m}$ particles, the flux decreased and its recovery was only partial. For the $0.1 \mu \mathrm{m}$ particle separation, the flux was stable and recovered almost completely. The particle rejection was low because of the small size of the particles relative to the pore size.

\subsection{Seawater Desalination by Air Gap Membrane Distillation (AGMD)}

Electro-spun PVDF membranes were prepared using a typical electro-spinning setup. A 18 wt. $\%$ 
solution of polyvinylidene fluoride (PVDF Kynar761, Elt-Chem USA) in dimethylformamide (DMF) was used as the polymer dope. The polymer solution was electro-spun at a rate of $2 \mathrm{~mL} / \mathrm{h}$. Six $\mathrm{mL}$ of the polymer solution was consumed to make around $0.15 \mathrm{~mm}$ thickness of the nano-fiber membrane. A high voltage (18 kV) was applied between the needle tip of the spinneret and the collecting metal plate (distance $18 \mathrm{~cm}$ ). The nanoliber mat was kept in a fume hood for 24 hours to dry at room temperature.

The diameter of the nanofiber nembrane was ca $1 \mu \mathrm{m}$. The $\mathrm{T}_{\mathrm{m}}$ (melt temperature) of the PVDF nanofiber membrane was $153^{\circ} \mathrm{C}$, while that of the dense PVDF film was $160^{\circ} \mathrm{C}$. The contact angle of the PVDF nanofiber membrane was $130^{\circ}$ while the contact angle of the dense PVDF flat film prepared by solvent evaporation at room temperature was $83^{\circ}$. The increase in contact angle for the nanofiber membrane is common for many polymeric materials.

The temperature difference is defined as $\Delta \mathrm{T}=$ $T_{2}-T_{1}$ where $T_{2}$ is the feed solution temperature and $T_{1}$ is the cooling water temperature. Aqueous sodium chloride solutions were used as feed
Sodium chloride concentrations both in feed and permeate solutions were determined through conductivity measurement.

Figures 1 shows flux versus temperature difference curves for $1 \%, 3.5 \%$ and $6 \% \mathrm{NaCl}$ concentrations. As the $\mathrm{NaCl}$ solution increases, the flux drops slightly indicating a small change of water vapour pressure with a change in $\mathrm{NaCl}$ concentration. As seen from Figure 1, the flux increases exponentially with an increase in temperature difference. This also reflects the water vapour pressure change with temperature. The highest water flux achieved at the highest temperature difference $\left(60^{\circ} \mathrm{C}\right)$ was $11-12 \mathrm{~kg} / \mathrm{m}^{2} \mathrm{~h}$.

Regarding $\mathrm{NaCl}$ rejection, there was a small change in $\mathrm{NaCl}$ rejection depending on the feed $\mathrm{NaCl}$ concentration. The $\mathrm{NaCl}$ separation data for various feed concentrations and different temperature differences were in a range of 98.799.9\%. In addition, $\mathrm{NaCl}$ concentration in permeate was determined to be between 110 to 280 ppmi, which is below the salt concentration limit for the drinking water. A 25 days separation test revealed that the membrane performance did not deteriorate during the long term experiment.

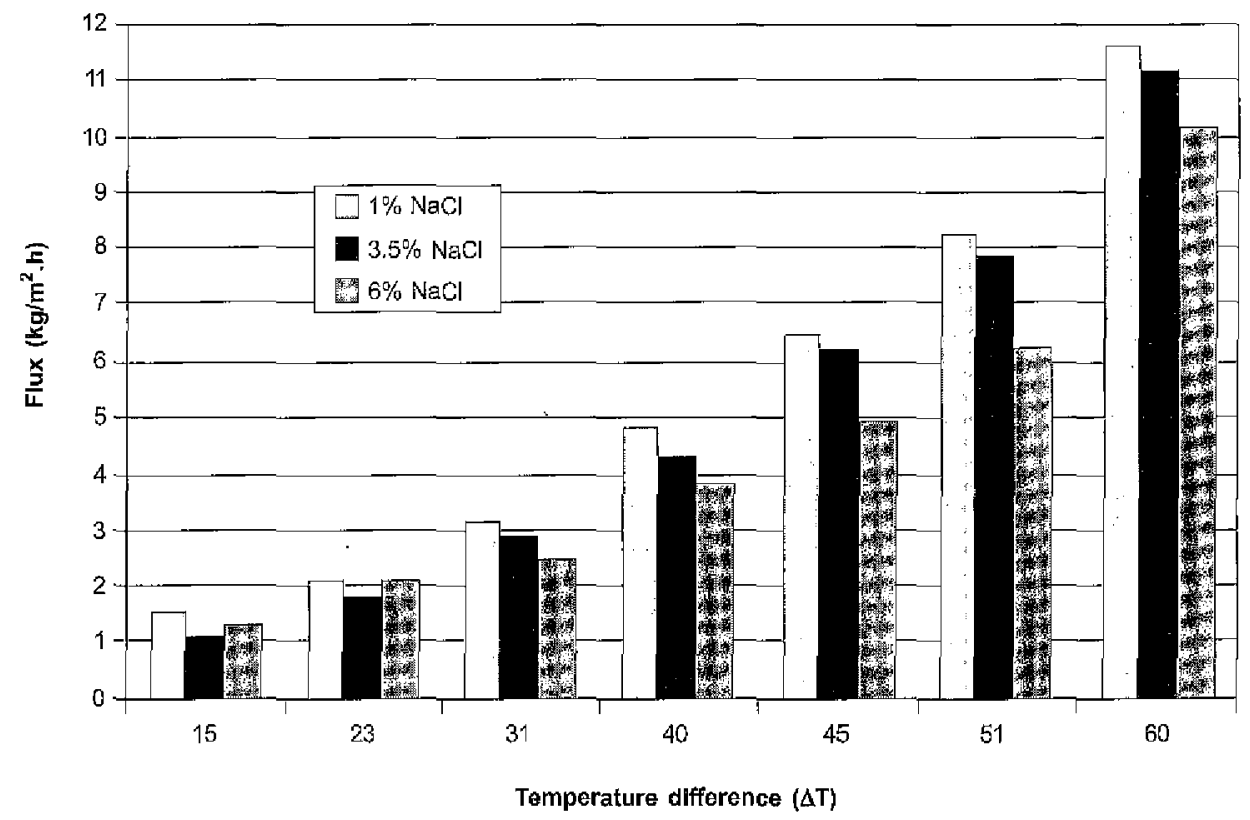

Figure 1 AGMD flux versus feed $\mathrm{NaCl}$ concentration at different temperature differences [4] 


\subsection{Trihalomethanes (THMs) and Haloacetic Acids (HAAs) Removal by Carbon Nanofiber Membranes}

Polyacrylonitrile (PAN, powder; density $1.184 \mathrm{~g} /$ $\mathrm{ml} ; \mathrm{T}_{\mathrm{g}} 85^{\circ} \mathrm{C}$; average $\mathrm{M}_{\mathrm{w}} 1.5 \times 10^{5}$ ) used in the study was from Sigma-Aldrich, Inc., St. Louis, MO, USA. PAN solutions in dimethyl formamide (8 to $12 \mathrm{wt} \%)$ were used for electro-spinning. The solution flow rate was $0.6-1.2 \mathrm{~mL} / \mathrm{h}$, the voltage was $14-18 \mathrm{kV}$ and the distance between the needle tip and the collector plate was approximately 19 $\mathrm{cm}$. A gauge 20 needle was used in the study. The average collection time was $1 \mathrm{~h}$. Increasing the collection time resulted in thicker membranes.

The collected nanofiber mats were placed in an air-circulated oven at $120^{\circ} \mathrm{C}$ for $3 \mathrm{~h}$ to remove any trace solvent that might be present in the nanofiber mat. After this the membranes were allowed to cool to room temperature and then heated to $250^{\circ} \mathrm{C}$ at a heating rate of $5^{\circ} \mathrm{C} / \mathrm{min}$. The membrane was then held at $250^{\circ} \mathrm{C}$ for at least $4 \mathrm{~h}$. Following this, the mats were carbonized by heating at a rate of $5^{\circ} \mathrm{C} /$ min up to temperature of between $400-500^{\circ} \mathrm{C}$ and kept for between $15 \mathrm{~min}$ to $4 \mathrm{~h}$ at this temperature, all under a nitrogen atmosphere. Thus, carbonized membranes (CMs) were fabricated.
The dead end cell was connected to a nitrogen cylinder that provided the applied pressure (1 psig) to force the liquid through the membrane. The rejection $(R)$ of chloroform and chloroacetic was calculated using the formula in Eq. 1.

$$
R=1-\frac{c_{p}-c_{w}}{c_{f}-c_{w}}
$$

where $c_{p}, c_{f}$, and $c_{w}$ are the concentration of chloroform or chloroacetic acid in the permeate, feed water (at time zero of filtration experiment) and the base concentration of the distilled water, respectively. Chloroform concentrations were determinecl using a Total Organic Carbon Analyzer with the UV-persulfate method (Phoenix 8000, Rosemount Analytical Inc. Tekmar Dohrmann Division, Santa Clara, CA USA). The concentration of chloroacetic acid was determined using a conductivity meter (Manufacturer, Place, Country).

ATR-FTIR spectra are presented in Figure 2. The aliphatic peaks of $\mathrm{C}-\mathrm{H}$ (bending), $\mathrm{C}-\mathrm{N}$ (stretching), and $\mathrm{C}-\mathrm{H}$ (stretching) are observed at 1454,2243 , and $2940 \mathrm{~cm}^{-1}$, respectively, for PAN nanofiber membranes dried at $120^{\circ} \mathrm{C}$ as seen in Figure 2 for spectra (a). These peaks are still

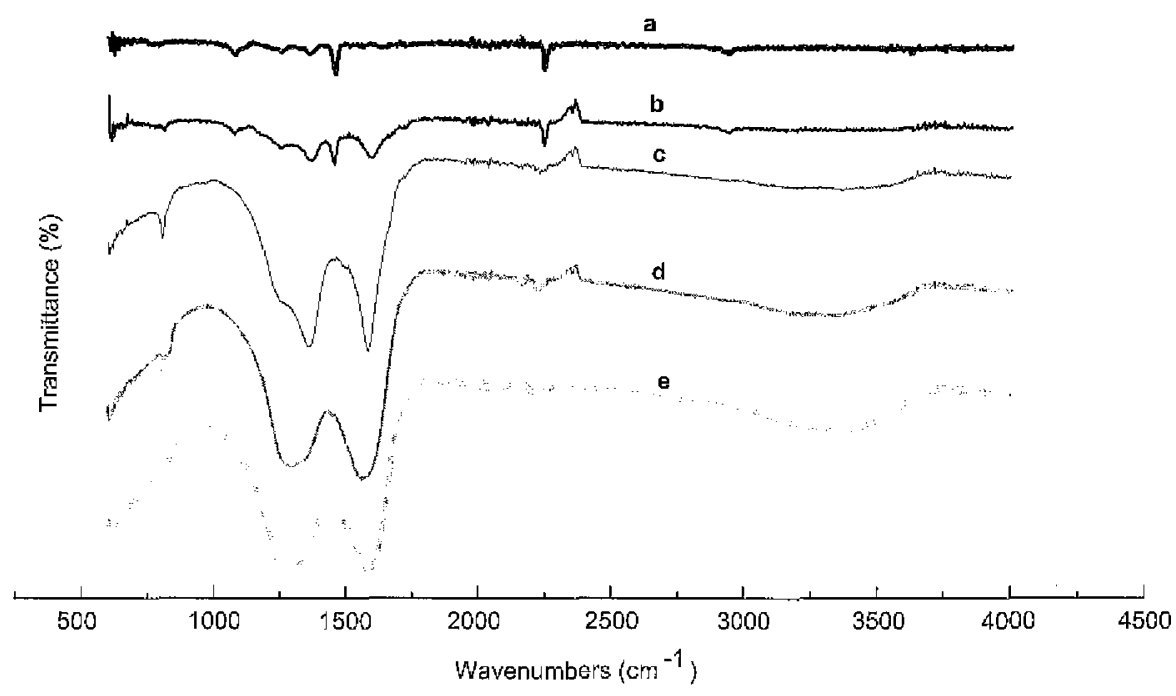

Figure 2 ATR-FTIR spectra of $10 \%$ PAN nanofiber membrane under conditions (a) air dried at $120^{\circ} \mathrm{C}$, (b) stabilized at $250^{\circ} \mathrm{C}$ for $6 \mathrm{~h}$, (c) carbonized at $400^{\circ} \mathrm{C}$ for $4 \mathrm{~h}$, (d) carbonize at $500^{\circ} \mathrm{C}$ for $\mu \mathrm{h}$ and (e) carbonized at $600^{\circ} \mathrm{C}$ for $\mu \mathrm{h}[6]$ 
observed when the nanofiber membrane is stabilized at $250^{\circ} \mathrm{C}$ as seen in (b). However, for the carbonized membranes as seen in (c) - (e), these pealks are not present. Instead, polynuclear peaks at 1367 and $1589 \mathrm{~cm}^{-1}$ are observed.

The contact angles of PAN air dried membranes at $120^{\circ} \mathrm{C}$ were found to be $107 \pm 3^{\circ}$. There was a slight increase in contact angle when the membranes were subjected to stabilization treatment and carbonization with contact angles of $128 \pm 5^{\circ}$ and $119 \pm 4^{\circ}$ respectively.

Differential Scanning Calorimetry (DSC) measurements were made in the temperature range of $40-160^{\circ} \mathrm{C}$. Electro-spun PAN nanofiber membranes had a glass transition temperature $\left(\mathrm{T}_{\mathrm{g}}\right)$ of $90^{\circ} \mathrm{C}$. No $T_{\mathrm{s}}$ value was observed in the range of temperatures tested for the carbonized nanofiber membranes. The evidence from the characterization data suggests that carbonization of the membranes takes place at temperatures in excess of $400^{\circ} \mathrm{C}$.

All membranes tested for filtration are made by the electro-spinning of $12 \mathrm{wt} \%$ PAN in DMF solvent, voltage of $14 \mathrm{kV}$ and flow rate of $0.6 \mathrm{~mL} /$ $h$. Typical performance data of chloroforn removal are given in Table 2.

Table 2 shows that the initial chloroform rejection is $100 \%$. This high chloroform removal is maintained until the permeate volume becomes $180 \mathrm{~mL}$. Eventually, chloroform rejection decreases to $0 \%$. This rejection pattern indicates that the

Table 2 The chloroform filtration performance of the $\mathrm{CM}$

\begin{tabular}{|c|c|c|}
\hline \multicolumn{3}{|c|}{$\begin{array}{c}\mathrm{CM} \text { at } 400^{\circ} \mathrm{C} \text { for } 4 \mathrm{hrs} \text {, membrane thickness } \\
0.48 \mathrm{~mm}\end{array}$} \\
\hline PWP $\left(L / \mathrm{m}^{2} h\right)$ & \multicolumn{2}{|c|}{$4157.77 \pm 173.80$} \\
\hline $\begin{array}{c}\text { Vol. of } \\
\text { permeate (ml) }\end{array}$ & $\begin{array}{c}\text { Flux } \\
\left(\mathrm{L} / \mathrm{m}^{2} \mathbf{h}\right)\end{array}$ & $\begin{array}{c}\text { Rejection } \\
(\%)^{+}\end{array}$ \\
\hline $0-60$ & 4241.80 & 100 \\
\hline $60-120$ & 4029.81 & 100 \\
\hline $120-180$ & 3699.40 & 100 \\
\hline $180-240$ & 3533.24 & 61.8 \\
\hline $240-300$ & 3384.27 & 0 \\
\hline
\end{tabular}

${ }^{+}$Feed solution: $100 \mathrm{ppm}$ of chloroform; pressure: 1 psi chloroform rejection is due to its adsorption to CM. From the experimental data chloroform adsorbed per unit weight of $\mathrm{CM}$ was calculated to be $0.665 \mathrm{gm}$ chloroform $/ \mathrm{gm}$ membrane. The filtration performance was further conducted with $20 \mathrm{ppm}$ chloroform concentration in feed using a membrane of even larger thickness $(-0.60 \mathrm{~mm})$.

Chloroacetic acid rejection was tested for various chloroacetic acid concentrations. Membrane thickness and carbonization condition were $0.18 \mathrm{~mm}$ and heating at $400^{\circ} \mathrm{C}$ for $4 \mathrm{~h}$, respectively. All membranes had a pure water permeation flux (PWP) of approximately $4500 \pm$ $200 \mathrm{~L} / \mathrm{m}^{2} . \mathrm{h}$. Four different feed waters of chloroacetic acid concentrations $100 \mathrm{mg} / \mathrm{L}, 50 \mathrm{mg} /$ L. $2.5 \mathrm{mg} / \mathrm{L}$ and $1 \mathrm{mg} / \mathrm{L}$ were separately tested. The rejection of chloroacetic acid is shown in Figure 3

The chloroacetic acid rejection decreases with its concentration in the feed water. At low concentrations of $1 \mathrm{mg} / \mathrm{l}$, high rejection of approximately $85 \%$ is observed, which decreases to about $40 \%$ after passing through $225 \mathrm{~mL}$ of feed through it. However, at higher concentrations e.g. $100 \mathrm{mg} / \mathrm{L}$, the solute rejection is approximately $9 \%$. In addition, at higher concentrations of chloroacetic acid the rejection reaches a stable

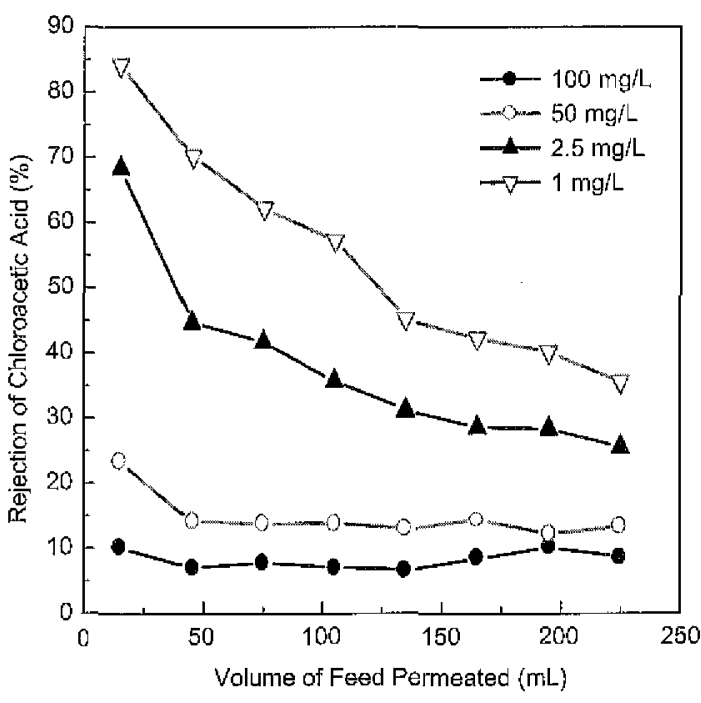

Figure 3 Rejection chloroacetic acid by $\mathrm{CM}$ at chloracetic acid concentrations of 100 , $50,2.5$ and $1 \mathrm{mg} / \mathrm{L}$ [6] 
value more quickly as compared to when the chloroacetic acid concentration is lower. This can be understood in terms of the adsorption kinetics of the membrane. The smaller concentration of chloroacetic acid implies that more can be adsorbed on the membrane as compared to when a higher concentration is used, which quickly adsorbs on the membrane surface.

\section{CONCLUSIONS}

Electro-spun nanofibrous membranes (ENMs) were found to be useful for the removal of particulate matters for the wastewater pretreatment, seawater desalination by air gap membrane distillation and for the removal of trihalomethanes and haloacetic acids by membrane adsorption after carbonization. Particularly ENMs possess high-flux rates and low transmembrane pressure. These characteristics are due to its (1) high porosity, (2) interconnected open pore structure and (3) tailorable membrane thickness.

\section{REFERENCES}

[1] Gopal, R., S. Kaur, C. Y. Feng, C. Chan, S. Ramakrișna, S. Tabe and T. Matsuura. 2007. Electrospun Nanofiburous Polysulfone Membranes as Pre-filters:
Particulate Removal. J. Membr. Sci. 289: 210-219.

[2] Gopal, R., S. Kaur, Z. Ma, C. Chan, S. Ramakrishna and T. Matsuura. 2006. Electrospun Nanofibrous Filtration Membrane. J. Membr. Sci. 281: 581-586.

[3] Feng, C. Y. 2009. Development of Novel Nanofiber Membranes for Seawater Desalination by Air Gap Membrane Distillation. Ph.D. Thesis. University of Ottawa.

[4] Feng, C., K. C. Khulbe, T. Matsuura, R. Gopal, S. Kaur, S. Ramakrishna and M. Khayet. 2008. Production of Drinking Water from Saline Water by Air-gap Membrane Distillation Using Polyvinylidene Fluoride Nanoliber Membrane. J. Membr. Sci. 311: $1-6$.

[5] Singh, G., D. Rana, T. Matsuura, R. M. Narbaitz and S. Tabe. Halogen-Material Removal in Drinking Water Using Carbonized Electro-Spun Nano-Fiber Membranes. $8^{\text {th }}$ World Congress of Chemical Engineering (WCCE8), Montreal, August 23-27, 2009.

[6] A Study to Investigate the Removal of Holoacetic Acids and Trihalomethanes from Drinking Water Using Carbon Nanofiber Membrane Filtration. Final Report Submitted to the Best Science Program, The Ministry of Environment, in February 2009. 